\title{
Challenges of Self-directed Clinical Skill Learning: Experience among Undergraduate Nursing Students in Malaysia
}

\author{
Airul Azizan Zainudin ${ }^{1}$, Norfadzilah Ahmad ${ }^{2}$, Hazwani Mohd Mohadis ${ }^{2, *}$ \\ ${ }^{1}$ Department of Professional Nursing Studies, Kulliyyah of Nursing, International Islamic University of Malaysia, Pahang, Malaysia \\ ${ }^{2}$ Department of Information System, Kulliyyah of Information and Communication Technology, International Islamic University of \\ Malaysia, Malaysia
}

Received August 31, 2019; Revised November 24, 2019; Accepted December 3, 2019

Copyright@2019 by authors, all rights reserved. Authors agree that this article remains permanently open access under the terms of the Creative Commons Attribution License 4.0 International License

\begin{abstract}
Purpose: This study aimed to explain the challenges experienced in self-directed clinical skill learning specifically in clinical skill laboratory among undergraduate nursing students in Malaysia. Methodology: A qualitative study using in-depth interview was conducted with 16 students attending Bachelor of Nursing in one of the public universities in Malaysia. The interview was open-ended to explore the overall perspective of the participants concerning their view about the problems and challenges they experienced on the self-directed clinical skill learning. Main Findings: Three major themes have been found on self-directed clinical skill learning which are 'lack of self-management', 'lack of desire for learning' and 'lack of self-control of learning'. The subthemes for 'lack of self-management' are poor time management, lack of communication with educator and lack of assessment of learning needs. The subthemes for 'lack of desire for learning' are not open to new ideas, lack of internal motivation, educator-dependent for seeking new knowledge and low quality of supporting learning materials. Lastly, the subtheme for 'lack of control of learning' is not realizing the importance of self-evaluation among undergraduate nursing students. Applications: Our findings informed academicians on various problems and challenges that occur in self-directed learning activities in clinical skill laboratory. These findings would assist them in preparing appropriate learning environment and clinical skill activities, which would improve the efficiency of knowledge and skill transfer and also enhance students' academic performance. Novelty/Originality: Previous studies have identified many challenging factors affecting clinical skill learning among nursing students such as clinical learning environment (e.g. physical, psychosocial, organizational) and students' learning process based on broad spectrum of perspective
\end{abstract}

without highlighting student-centred point of view. Thus, in our study, we have attempted to explore how nursing students describe the challenging experience of undertaking the process of learning clinical skills from the perspective of a self-directed learner.

Keywords Nursing Education, Clinical Skill Learning, Self-directed Learning, Nursing Student, Qualitative, Interview

\section{Introduction}

The incorporation of self-directed learning approaches within nursing programme in university has benefited students in promoting lifelong learning. Self-directed learning is defined as, “ . . a a process in which individuals take the initiative, with or without the help of others, in diagnosing their learning needs, formulating learning goals, identifying human and material resources for learning, choosing and implementing appropriate learning strategies, and evaluating learning outcomes" (Knowles, 1975). Research in self-directed learning in nursing education was becoming popular based on Fisher's Self-Directed Learning Readiness Scale for Nursing Education (SDLRNE), constituting three important components which are self-management of learning, self-control of learning and desire of learning (Fisher \& King, 2010; Fisher, King, \& Tague, 2001).

Clinical learning experience among students is shaped from multiple elements of academic programme, is commonly valued by the nursing profession because it combines theoretical and practical learning experience which 
allows the student to combine their sensory, motor and cognitive learning processes. Nursing students skill performance is influenced by the factors surrounded the clinical learning area for example the physical, psychosocial and organizational (Haraldseid, Friberg, \& Aase, 2015; Khoza, 2015). Students have devoted time and energy in essence of learning safe nursing practice for instance handling sterile procedure and preventing medication errors (Sulosaari et al., 2015) nevertheless quality of patient care is still can be compromised (Baraz, Memarian, \& Vanaki, 2015). Since nursing education is becoming more complex in terms of clinical skill acquisition, nowadays there are emerging learning approaches that are becoming popular which include self-directed learning. Based on these reasons, nursing training has shifted from routine practice of tasks in the hospital, to evidence-based practice in university such as practicing in clinical skill laboratory (Ewertsson, Allvin, Holmström, \& Blomberg, 2015). At present, the nursing curriculum throughout Malaysia's universities and colleges is accredited by the Nursing Board Malaysia (2015).

In provision of self-directing clinical skill learning, the organizational factors are important to provide imperative learning environment such as curriculum design and learning resources. Besides, the amount of subject and time allocated to practice in nursing curriculum have influenced the perceptions of nursing students towards learning clinical skill (O’Mara, Mcdonald, Gillespie, Brown, \& Miles, 2014). Learning clinical skill can be intimidating with a large number of students (Arkan, Ordin, \& Dilek, 2018) sharing the same learning place. The need of adequate resource is important to prepare the environment as realistic as real clinical area. Besides, the authenticity of learning environment is pivotal as it affects experience in acquiring skill competency (Haraldseid et al., 2015; Houghton, Casey, Shaw, \& Murphy, 2012; McCallum, 2007). It is understood that nursing students are confused with the learning expectation of the program since they have to link the theory learned in the classroom into the role that they practice in clinical area (Arkan et al., 2018; Serçekus \& Bas, 2016). Hence, without authenticity of learning environment, knowledge transfer is halted and the theory-practice gap cannot be minimized. From the perspective of self-directed learner, any deficiencies in learning environment can disrupt the desire to learn, demotivate learning process and limit the ability of students to control their learning.

Besides, challenges due to relationship with lecturer, clinical instructor and nurses are interpersonal (Bryan, Weaver, Anderson-johnson, \& Lindo, 2013; Lawal, Weaver, Bryan, \& Lindo, 2016), as the connection they share in provision of developing clinical skill. To be self-directed learner, interpersonal criteria are important. Studies have shown that relationship between nurse educators and nursing students has an effect on the clinical skill performance (Bryan et al., 2013; Serçekus \& Bas, 2016), especially it affects the management of learning and desire to learn the clinical skill. Assessment on the learning environment among students is a need before a student can embark on subsequent self-directed learning process. The literature shows that nurse educators' credibility and attitude are jeopardized by ignoring their roles such as lack of preparation on program expectation (O’Mara et al., 2014; Yousefy, Shayan, \& Mosavi, 2012), selective in teaching role (Yousefy et al., 2012), and improper communication with the students (Jamshidi, Molazem, Sharif, Torabizadeh, \& Kalyani, 2016). As a result of this, the students are also significantly affected by uncertainties on the teaching styles. It can be worsening to the extent that some would not receive proper answer and be ignored (Arkan et al., 2018; Khoza, 2015; O’Mara et al., 2014; Serçekus \& Bas, 2016). Thus, from the point of view of self-directed learning, learning goals can be accomplished by collaboration with nurse educator through proper activity planning and use of available resources.

Challenges in self-directed clinical skill learning also are contributed by the students themselves. Students are lack of readiness to learn clinical skill because they are unprepared in knowledge, practice (Arpanantikul \& Pratoomwan, 2017) and communication skill (Jamshidi et al., 2016). Students did not memorize, were unable to apply skills and focused too much on a specific procedures only, which are among the factors contributing to the problem (Arpanantikul \& Pratoomwan, 2017). Additionally, students' motivation as a building block of learning experience is intimidated much by lack of faculty relationship (O'Mara et al., 2014), lack of support (Arkan et al., 2018), stress of new experience (Arpanantikul \& Pratoomwan, 2017) and inferiority complex (Jamshidi et al., 2016). As a result, students exhibit loss of interest in learning such as fear to ask question, loss of self-confidence (Arkan et al., 2018; O’Mara et al., 2014) and making poor judgment (Arpanantikul \& Pratoomwan, 2017). When there is less supervision from the educator. students may not pay full attention and as a result, it leads to anxiety during clinical evaluation (Arkan et al., 2018). This further reduces the self-directedness of learning.

Even though nursing programme guideline by the Ministry of Health is compulsory to follow, but until now, little has been known about the challenges nursing students faced in self-directed clinical skill learning in Malaysia. In order to provide optimal guidance on efficient learning implementation, experience among nursing students in self-directed clinical skill learning should be addressed and taken into consideration. Accordingly, in this study, we aimed to explain the challenges from the point of view of self-directed learning approach experienced by undergraduate nursing students in Malaysia.

\section{Methodology}

\subsection{Research Design}

This study implements a qualitative study design to enable 
participants to freely express their thoughts on self-directed clinical skill learning problem. In-depth interview is one of the approaches in qualitative design which permits interviewer to investigate sensitive and complex questions, further helps participants to respond easily. By being physically present, the interviewer can decrease the number of "don't know" and "no answer" responses by probing for additional responses. Besides, interviewers can clarify questions to participants when needed. This interview is open-ended to explore the overall perspective of the participants concerning their view about the problems or challenges they experienced on the self-directed clinical skill learning. Two postgraduate students have participated in pilot study in order for the researcher to be familiar with the flow of the interview.

\subsection{Participant}

A total of 16 students attending Bachelor of Nursing in one of public universities in Malaysia were recruited onto the study. The inclusion criteria comprised: 1) undergraduate nursing student of the university, 2) completing at least one semester for clinical skill practice, and 3) "active" student status in the university database. The students are comprised of all volunteers, which represent each student batch (4 students $\mathrm{x} 4$ batches in total) in the program.

\subsection{Data Collection}

Data were collected using in-depth interview. This study employed semi-structured interview guide which can be used to unearth rich descriptive data especially information on the nursing students' clinical skill learning experience. An interview guide was created to help the researcher to determine the order of questions related to of self-directed clinical skill learning. The interviews were audio-recorded. All interview sessions with the students were made by the first author of the study.

The audio recorded interviews were transcribed verbatim. The transcription of the interviews was analysed by using thematic analysis. Data were analysed by using NVivo 12 . We first coded the transcribed data and evaluated its inter-rater reliability by executing the 'Coding Comparison' function of the software, in which it generates Cohen's Kappa coefficient value. A value of 0.80 was considered as perfect agreement and hence was finalized as challenging factors that influenced self-directed clinical skill learning among undergraduate nursing students.

\subsection{Data Analysis}

Thematic analysis was utilized in this study, known as an important approach to identify and recognize the challenges experienced by the nursing students in self-directed clinical skill learning. Moreover, it is a method for a researcher to inspect qualitative data followed by identifying and reporting patterns of the qualitative data (Braun \& Clarke, 2006). The popular six steps of analysing this qualitative data is started with being familiar with the data, followed by coding, searching for the themes, reviewing the themes, defining the themes and reporting.

\subsection{Rigour of Data}

To ensure trustworthiness during the analysis as recommended by Lincoln \& Guba (1985), we analysed and repetitively discussed the coding and their interpretation. For data validation, the manuscripts were reviewed and processes involved in coding were justified. Extracted codes were reviewed by the second coder who was familiar with the analysing processes of qualitative research and the accuracy of the data coding process was evaluated. Besides, by providing sufficient time for the researcher to collect data and involving expert in reviewing the analysis and interpretation, it will improve credibility of the study. Limiting potential bias was made by bracketing in which reflexivity was made before the study began. Besides, the researcher also took notes on the participants' responses during interviews to help to confirm the objectivity and conformability of the study. The findings of this study were generated based on students' own ideas and experience.

\section{Result}

The themes emerged from undergraduate nursing students' experiences of clinical skill learning from the perspective of self-directed learning were identified and interpreted as 'lack of self-management', 'lack-of desire for learning' and 'lack of self-control of learning'. All these three (3) themes are related to each other and by looking at the pattern of the data it helps us to reach an understanding of the challenges experienced by the nursing students in self-directing their clinical skill learning particularly in clinical skill laboratory.

\subsection{Lack of Self-management Skill}

Self-management skill has been noticed as the capacity of the student in implementing set goals and how the students can effectively manage the resources relevant for their learning. There are three subthemes being addressed related to self-directed clinical skill learning among undergraduate nursing students: 1) poor time-management, 2) lack of communication in learning and 3) lack of assessment in learning needs.

\subsubsection{Poor Time Management}

A good time management required a student to plan and consciously control the activities in order to increase the efficiency and productivity in any life events. A student from Year 2 addressed one of the weaknesses in self-management of time that is prioritizing learning activities. She insisted difficulty to practice skill procedure in the skill laboratory due to the load of assignments as saying: 
... we need to do a lot of hands-on practice but because of lack of time [and] so many assignments, so we don't have much time to do the hands-on [practice]... (ID\#15, Y2S1)

Likewise, a student reported could not manage to perform skill practice due to the need to involve in cocurricular activities in the campus:

... when I was in Year 2, it is a busy year and I was not able to practice in skill lab, I have to handle many programmes. (ID\#16, Y4)

Besides, the lack of time management is influenced by the lack of awareness among nursing students to address the academic timetable designed for them. A respondent said:

...because we used [Self-directed Learning] slot for doing assignment. (ID\#1, Y3)

\subsubsection{Lack of Communication with Educator}

A good management of learning required a good collaboration and communication with the educators. However, clinical skill learning activities were poorly accepted by the student when there is a lack of understanding in communication. A response from a student has shown that the students were poorly prepared on how to deal with unexpected clinical skill assessment by saying:

...we do the procedure but the lecturer expects us to do different things. Like I just said, we learn from others and are assessed by others. (ID\#15, Y2S1)

\subsubsection{Lack of Assessment of Learning Needs}

The nature of the clinical skill procedures involves complex and long procedures such as sterility-related procedures. A procedure can be managed well if the students can plan and prepare the learning effectively. One student has commented that the magnitude of learning is becoming more complicated throughout the year of study as said:

At first time, learning the procedure during my first ....is simple so we don't need a lot of practice. But for this semester... the procedure is quite complicated and there are a few factors that we need to take care of, like the sterility, the technique ... (ID\#15, Y2S1)

Students can be self-directed in learning if they make assessment on the strengths and weaknesses of their learning environment especially the learning resources. Apart of these interview findings, students were aware of the difficulties such as crowded learning session and limited equipment, but they were found to be lack of efforts to plan for fulfilling their learning needs. The examples of the responses were:

...It's quite hard for us, we have 70 students so every student wants to practice, it's impossible. (ID\#14, Y2S1)

... when we want to practice skin traction, plaster...is very limited, we [are]... competing [each other] to do that thing... those who [came] late didn't get the [chance to] experience. (ID\#13, Y2S1)

\subsection{Lack of Desire to Learn}

'Desire to learn' associates motivation level of the students with their capability of appropriately seeking new information, in consideration of improved learning needs. There are four subthemes that can be identified to inform the characteristics of this theme which are a) not open to new ideas, b) lack of internal motivation, c) educator-dependent for seeking new information and d) low quality of education material.

\subsubsection{Not Open to New Ideas}

Many lecturers and clinical instructors have different clinical backgrounds in their careers such as clinical specialties they had been worked with before. This diversity can help the institution to encourage a teaching and learning atmosphere that promotes enquiry in which subsequently new ideas can emerge. However, in this study the students found it was an intimidation rather than opportunity for getting new idea to be more self-directed learner.

...there have been issues whereby the procedures are not being agreed by both sides. That's why some procedures, ok let's say for the injection of Hep B and also BCGs, some say we need to use dry swab, some say wet swab, so it needs to be agreed by both sides... (ID\#5, Y4)

In addition, a part of faculty-based procedure checklist provided, the faculty also subscribed to academic material from international vendor to help the student to learn. However, one student issued there were too many versions of procedure checklists provided which make it difficult to adapt for Malaysian context.

It is not from the faculty version and sometimes it is different because the Clinical Skill [web program] is based on American, Europe, so sometimes there are different guidelines but same procedure. (ID\#13, Y2S1)

\subsubsection{Lack of Internal Motivation}

A nursing student must have the ability to regulate and adapt to the demands of learning situation in order to achieve learning goals and values. In the process, the student would realize what is happening on their learning and how to adjust with their own behaviour with the learning environment. Anxiety is one of the major findings among nursing students during clinical skill learning. Generally, the reason for such behaviour to happen is because of being afraid to do wrong. ... I really think whenever we get [to be] assessed, we will not be doing okay... we feel like very scared so we tend to do a lot of mistakes. (ID\#8, Y2S2)

Loss of focus and getting confused is another contributor for low motivation in learning a skill. A student expressed that the problem occurred due to the opportunity to observe and learn during demonstration of the procedure that is 
restricted.

But when there are many, crowded people I would ... lose focus. (ID\#13, Y2S1)

\subsubsection{Educator-dependent for Seeking New Information}

One of the criteria of proactive learner is taking responsibility for their learning activities, with or without the help of others. Students whose lack of readiness in self-directed learning tend to be teacher-centred. In this study, it is noticed that students rely much on their educator to drive learning activities.

The lecturer also has their tight schedule, they only ask us to go to the skill laboratory and the clinical instructors only monitor us, so usually the clinical instructors will give their feedback. (\#15, Y2S1)

\subsubsection{Low Quality of Supporting Learning Material}

The procedure checklist provides step by step process for a student in completing the clinical skill procedure through a safe practice. However, in this study the content of the procedure checklist is found to be inaccurate and incomplete, thus affecting the progress of learning among students.

Sometimes as I know, the information from the book is a little bit older ... sometimes few things weren't in the book or sometimes there is even a wrong fact from the book... (ID\#11, Y2S2)

On a parallel, it has been informed that log book system was found to be lacked in terms of accessibility. Since it is stored in the clinical skill laboratory, the accessibility to utilize the book is limited, thus self-monitoring of learning is difficult to be performed.

Usually log book, they store in skill laboratory, so basically when we want to use the book so we need to ask from the person at skill laboratory to give us the book... (ID\#7, Y2S2)

\subsection{Lack of Self-control of Learning}

The third theme of this study is the lack of self-control of learning among undergraduate nursing students. Self-control addresses the process by which a student determines its own self-determination and forms its own learning objectives, takes responsibilities, acknowledges his own capacities and makes his own decisions. The finding of the interview has found that the students do not realize the importance of self-evaluation in their clinical skill learning, which reflects the low degree of self-directed learning.

\subsubsection{Not Realizing the Importance of self-evaluation}

Log book is utilized to record the procedures being practiced in clinical skill laboratory. A student admitted has forgotten to utilize the log book since she was in Year 2, as admitted:

Honestly, right now, no. Because last time I remember I only use the log book until second year. But when entering third year, I'm not sure. I even don't know where the book is... (ID\#7, Y4)

Besides, one has confessed that students have taken for granted to get educator verification even without practicing the procedure.

...some of my friends sometimes don't really do the procedures correctly. But they will say to the lecturer that they have done it and the lecturers or clinical instructor just gave the signature to them. (ID\#8, Y2S2)

The students had more worries about how to fulfil the signature than how much they can learn. Inversely, there are also students who make the skill practice for the sake of learning but weren't interested in fulfilling the logbook due to the uneventful process.

This did not affect the performance because our practice wasn't based on what is in the log book. Some of the students practice but they did not get the signature for the log book. (ID\#14, Y2S1)

In addition to that, one has confessed that students have taken for granted to get educator verification even without practicing the procedure.

...some of my friends sometimes don't really do the procedures correctly. But they will say to the lecturer that they [have] done it and the lecturers or clinical instructor just gave the signature to them. (ID\#8, Y2S2)

\section{Discussion / Analysis}

\subsection{Self-management of Learning}

Since the demand for healthcare is increasing, the proliferation of new nursing schools also propagates more new nurse graduates. The growth number of students is seen not proportional to the increases of resources for clinical skill learning such as physical infrastructures and clinical teaching equipment (Asirifi et al., 2017). Big number of students can disturb the clinical skill learning process. The pressures originated from learning environment are numerous, which is not only caused by a large number of students competing each other to practice, but also struggles with time limitation to complete procedure practices, subsequently has affected students' self-management of learning. It is necessary to effectively tailor the needs of the students' learning with the learning resources they have. O'Mara et al. (2014) has described time limitation problem by referring to the design of the curriculum along with the amounts of courses, types of clinical experience and competing demands from concurrent courses. In relation of the interview, skill for assessing learning situation and managing time is important for students to develop. A student with high level of self-directed learning attitude would have responded with the readiness to prioritize self-identified goals, thus to remove the limitations found in learning (Rensburg \& Botma, 2015). 
A self-directed learner should possess consciousness with responsibility in learning, show curiosity, appear organized in managing time effectively and anticipate in problem solving (Rensburg \& Botma, 2015).

Besides, it is understood that the students always misjudged on what the educators really expected on them for assessment is different with what is being understood by them, as this issue has been found similar with few other studies (Haraldseid et al., 2015; O’Mara et al., 2014), which has led students' practical capability that is jeopardized because of inconsistent information they receive. Arkan et al., (2018) noticed this issue as communication method problem. Moreover, being overly critical or unpredicted in giving feedback is a big challenge (O'Mara et al., 2014). Interpersonal communication skill is acknowledged as how students can shape their interaction skill with others in view of promoting their own learning. It is argued that the ability to interact with others is an important part of nursing students' lifelong learning ability (Su-Fen, Chien-Lin, Lin, \& Jane, 2010). Douglass \& Morris (2014) suggested the most effective way to empower students' self-directed learning be by identifying their learning goals and their subsequent implementation strategies.

Moreover, resource support is a factor that can help to improve mental images because authenticity of learning environment is a determining component in practice (Haraldseid et al., 2015). In a parallel, for some students a complex procedure may take a little longer for them to master (Gonzalez \& Kardong-Edgren, 2017) compared to others. It is advised that overlearning or additional training time be recommended as it will link to better retention of knowledge and skill. Overall, the interview reported students had few challenges in self-management of learning clinical skill.

\subsection{Desire of Learning}

Different experience background among educator has affected the magnitude of learning among students. The students have difficulties in accepting several opinions on clinical skill procedures due to different experience possessed by every educator. It is opposed the character of a self-directed learner who accepts the freedom to learn what has been considered important for themselves. Likewise, self-directed learning also required openness to learning opportunities (Rensburg \& Botma, 2015). The lack of openness to accept new ideas from the educators might be a result of learning culture among students who often regard the lack of readiness for creativity and desire for learning.

Then, motivation is the driving force underlying the change of behaviour. Fear and anxiety can have impact on psychosocial condition that may cause the students to be less involved in learning activities (Baraz et al., 2015). Inner motivation is driven by one's needs, values and feelings, which refers to do something because it is inherently interesting or enjoyable (Ryan \& Deci, 2000). Students are more likely to work towards goals they set for themselves if the behaviour change is driven by inner motivation, whereas external motivation is driven by other people, reward or penalties. Psychological empowerment can be enhanced as it has been identified as primary predictor for learning (Safari, Haghighib, Rastegara, \& Jamshidi, 2011). Encouraging students to be participated in development of course requirement can improve internal motivation to learn (Douglass \& Morris, 2014; Herman, 2012). Therefore, desire of learning is in-line with the move towards sustained self-directedness of learning, which improves the clinical skill performance of a nursing student.

\subsection{Self-control of Learning}

Not many of studies have discussed the usage of supported documents (e.g. procedure logbook and procedure checklist) to generate more evidence to use recording of learning experience (Joshi, Gupta, \& Singh, 2015). In fact, most of the nursing schools use this document to monitor the students' performance and adherence to the learning activities. The document used as part of monitoring program for self-evaluation is important for self-control of learning, and unfortunately has not been perceived as effective and efficient. As a consequence, the students have weak control over their learning through self-evaluation activities. Due to lack of user-friendliness and poor implementation, students missed many important skill activities and opportunities to self-assess their performance for future improvement. One of the solutions for this is to provide easily accessible program or application for the student to use anywhere and anytime. It must also consider to expedite the verification process without taking too much time, improve effectiveness of each practical session and lastly increase satisfaction on self-assessment of learning.

\section{Conclusions}

This research explored challenges of self-directed clinical skills learning among Malaysian undergraduate nursing students. Some of the findings are supportive of the literature while few are deemed to be a new finding based on Malaysian context of nursing education. In order to visualize clear pathway of self-directed clinical skill learning, the students must consider the essential components as a self-directed learner by instilling the good self-management of learning, enjoy and have desire to learn and collaborative in clinical skill learning, and be conscious with learning needs through self-control of learning.

\section{Limitation and Study Forward}

Since sampling of the research consists of one university, the researcher only involves experiences of students who learn in this clinical learning setting. Factors affecting 
clinical skills learning might differ in other locations and different settings of the universities.

For future work, the suggestion that can be considered may include doing more qualitative studies towards several public and private universities. Other than face-to-face in-depth interview, the researchers are encouraged to do focus group discussion, document analysis and observation studies with regards to the nursing students' self-direction of clinical skill learning.

\section{Acknowledgements}

The research is funded by International Islamic University of Malaysia under Research Initiative Grant Scheme (RIGS), project ID: RIGS17-068-0643.

\section{REFERENCES}

[1] Arkan, B., Ordin, Y., \& Dilek, Y. (2018). Undergraduate nursing students ' experience related to their clinical learning environment and factors a ff ecting to their clinical learning process. Nurse Education in Practice, 29, 127-132. https://doi.org/10.1016/j.nepr.2017.12.005

[2] Arpanantikul, M., \& Pratoomwan, A. (2017). Clinical Learning Experiences of Second-Year Thai Nursing Students : A Phenomenological Study. Pacific Rim Int J Nurs Res, 21(2), 121-134.

[3] Asirifi, M., Ogilvie, L., Barton, S., Aniteye, P., Stobart, K., Bilash, O., ... Kwashie, A. (2017). Assessing challenges of clinical education in a baccalaureate nursing program in Ghana. Journal of Nursing Education and Practice, 7(10), 109-118. https://doi.org/10.5430/jnep.v7n10p109

[4] Baraz, S., Memarian, R., \& Vanaki, Z. (2015). Learning challenges of nursing students in clinical environments: A qualitative study in Iran, 4(August), 1-9. https://doi.org/10.4103/2277-9531.162345

[5] Bryan, V. D., Weaver, S., Anderson-johnson, P., \& Lindo, J. M. L. (2013). The effect of interpersonal relationships between nursing students and lecturers on learning outcomes at a Jamaican nursing school. Caribbean Journal of Nursing, 1(1), 41-48.

[6] Douglass, C., \& Morris, S. R. (2014). Student perspectives on self-directed learning. Journal of the Scholarship of Teaching and Learning, 14(1), 13-25. https://doi.org/10.14434/josotl.v14i1.3202

[7] Ewertsson, M., Allvin, R., Holmström, I. K., \& Blomberg, K. (2015). Walking the bridge: Nursing students' learning in clinical skill laboratories. Nurse Education in Practice, 15(4), 277-283. https://doi.org/10.1016/j.nepr.2015.03.006

[8] Fisher, M., \& King, J. (2010). The self-directed learning readiness scale for nursing education revisited: A confirmatory factor analysis. Nurse Education Today, 30(1), 44-48. https://doi.org/10.1016/j.nedt.2009.05.020

[9] Fisher, M., King, J., \& Tague, G. (2001). Development of a self-directed learning readiness scale for nursing education, 516-525. https://doi.org/10.1054/nedt.2001.0589

[10] Gonzalez, L., \& Kardong-Edgren, S. (2017). Deliberate practice for mastery learning in nursing. Clinical Simulation in Nursing, 13(1), 10-14. https://doi.org/10.1016/j.ecns.2016 .10 .005

[11] Haraldseid, C., Friberg, F., \& Aase, K. (2015). Nursing students' perceptions of factors influencing their learning environment in a clinical skills laboratory: A qualitative study. Nurse Education Today, 35(9), e1-e6. https://doi.org/10.1016/j.nedt.2015.03.015

[12] Herman, G. L. (2012). Designing contributing student pedagogies to promote students ' intrinsic motivation to learn, 22(4), 369-388.

[13] Houghton, C. E., Casey, D., Shaw, D., \& Murphy, K. (2012). Staff and students' perceptions and experiences of teaching and assessment in Clinical Skills Laboratories: Interview findings from a multiple case study. Nurse Education Today, 32(6), e29-e34. https://doi.org/10.1016/j.nedt.2011.10.005

[14] Jamshidi, N., Molazem, Z., Sharif, F., Torabizadeh, C., \& Kalyani, M. N. (2016). The challenges of nursing students in the Clinical Learning Environment: A qualitative study. The Scientific World Journal, 2016, 1-7.

[15] Joshi, M. K., Gupta, P., \& Singh, T. (2015). Portfolio-based Learning and Assessment. Indian Pediatrics, 52, 231-235.

[16] Khoza, L. B. (2015). Nursing Students ’ Perception of Clinical Learning Experiences Nursing Students 'Perception of Clinical Learning Experiences. Journal of Human Ecology, 51(1-2), 103-110. https://doi.org/10.1080/09709274.2015.1 1906900

[17] Knowles, M. S. (1975). Self-regulated Learning: A guide for learners and teachers. New York: The Adult Education Co.

[18] Lawal, J., Weaver, S., Bryan, V., \& Lindo, J. L. M. (2016). Factors that influence the clinical learning experience of nursing students at a Caribbean school of nursing, 6(4). https://doi.org/10.5430/jnep.v6n4p32

[19] Lincoln, Y. S., \& Guba, E. G. (1985). Naturalistic Inquiry. Sage Publications, Inc.https://doi.org/10.1007/s00396-002-0 735-7

[20] McCallum, J. (2007). The debate in favour of using simulation education in pre-registration adult nursing. Nurse Education Today, 27(8), 825-831. https://doi.org/10.1016/j.nedt.2006.1 0.014

[21] Nursing Board of Malaysia. (2015). Standard Operating Procedures for Approval/ Accreditation of Nursing Programmes.

[22] O’Mara, L., Mcdonald, J., Gillespie, M., Brown, H., \& Miles, L. (2014). Challenging clinical learning environments: Experiences of undergraduate nursing students. Nurse Education in Practice, 14(2), 208-213. https://doi.org/10.1016/j.nepr.2013.08.012

[23] Rensburg, G. H. Van, \& Botma, Y. (2015). Bridging the gap between self-directed learning of nurse educators and effective student support. Curationis, 38(2), 1-7. https://doi.org/10.4102/curationis.v38i2.1503

[24] Ryan, R. M., \& Deci, E. L. (2000). Intrinsic and Extrinsic 
Motivations: Classic Definitions and New Directions. Contemporary Educational Psychology, 25, 54-67. https://doi.org/10.1006/ceps.1999.1020

[25] Safari, K., Haghighib, A. S., Rastegara, A., \& Jamshidi, A. (2011). The relationship between psychological empowerment and organizational learning. Procedia - Social and Behavioral Sciences 30, 851-866. https://doi.org/10.1002/jcop.21578

[26] Serçekus, P., \& Bas, H. (2016). Nursing students ’ perceptions about clinical learning environment in Turkey. Nurse Education in Practice, 17, 134-138. https://doi.org/10.1016/j.nepr.2015.12.008

[27] Su-Fen, C., Chien-Lin, K., Lin, K.-C., \& Jane, L.-H. (2010). Developing Online Continuing Education Content for Enhancing Caring Among Taiwan Nurses. International Journal of Nursing Studies, 47(9), 1152-1158. https://doi.org/10.3928/00220124-20130301-26

[28] Sulosaari, V., Huupponen, R., Hupli, M., Puukka, P., Torniainen, K., \& Leino-kilpi, H. (2015). Factors associated with nursing students medication competence at the beginning and end of their education. BMC Medical Education, 15(223), 1-11. https://doi.org/10.1186/s12909-01 5-0513-0

[29] Yousefy, A., Shayan, S., \& Mosavi, A. (2012). Developing a clinical performance logbook for nursing students receiving cardiac care field training. Journal of Education and Health Promotion, 1(March), 7. https://doi.org/10.4103/2277-9531. 94415 